\title{
Implementação da Reforma Sanitária: a formação de uma política '
}

\section{Health Reform Implementation and Policy Formation '}

\author{
Telma Maria Gonçalves Menicucci \\ Doutora em Ciências Humanas: Sociologia e Política \\ Professor/pesquisador da Fundação João Pinheiro \\ Email: telma.menicucciðfjp.mg.gov.br \\ 10 artigo é extraído da tese de doutorado da autora cujo título \\ é: Público e privado na política de assistência à saúde no Brasil: \\ atores, processos e trajetória, defendida na UFMG em 2003 e \\ contemplada com Menção Honrosa no concurso CNPq-ANPOCS \\ de obras científicas e Teses Universitárias em Ciências Sociais, \\ Edição 2004. Versão preliminar foi apresentada como Texto para \\ Discussão n. 19 da Escola de Governo da Fundação João Pinheiro \\ em outubro de 2005.
}

\section{Resumo}

Este artigo procura interpretar o processo de implementação da reforma do sistema de saúde ocorrida na década de 1990. A implantação de uma política é dotada de autonomia e envolve decisões, além de ser um processo de adaptação em função das mudanças do contexto, portanto, sua implementação exige decisão e iniciativa governamental, e instrumentos para efetivá-la, entre os quais a disponibilidade de recursos financeiros e o suporte político organizado, particularmente, por parte dos grupos sociais afetados positivamente. 0 processo de implementação da reforma da política de saúde não é simplesmente a tradução concreta de decisões, mas um processo ainda de formulação da política de saúde. Durante esse processo, tiveram grande importância não apenas os efeitos do contexto político-econômico de ajustes e a reconfiguração da agenda pública, mas principalmente os efeitos de feedback das políticas de saúde anteriores, que se traduziram na ausência de suporte político, no subfinanciamento e na incapacidade de publicização da rede de serviços, os quais funcionaram como constrangimentos à implementação completa da reforma nos termos de seus formuladores. Dentro desses limites, foram tomadas decisões cruciais que redefiniram a reforma, sendo as mais significativas o estabelecimento do marco regulatório da assistência privada, que explicita a segmentação e derruba formalmente as pretensões universalistas, e as relacionada ao financiamento, que ainda configurava objeto de disputa. 0 resultado foi a consolidação de um sistema de saúde dual - público e privado.

Palavras-chave: Política de saúde; Implementação; Suporte político; Financiamento; Efeitos de feedback. 


\section{Abstract}

This paper analyses the process of implementation of the health system reform in the 1990s. The starting point is the proposition that policy implementation is endowed with autonomy and involves decisions, apart from being a process of adaptation to changes in context; implementation requires governmental decision and initiative and tools to make it effective, among them the availability of financial resources and organized political support, especially from those groups that benefit more directly. The process of implementation of the health system reform was not simply a concrete translation of decisions, but also a process of health policy design. In it, the effects not only of adjustments in the political and economic contexts and of the reconfiguration of the public agenda, but mainly the feedback effects of previous health policies could be felt. The latter translated themselves into the absence of political support, underfinancing and the incapacity to create a public network of services. They acted as constraints to the full implementation of the reform, as it was conceived by its formulators. Within these limits, crucial decisions were made, which redefined the reform, the most important being, on the one hand, the creation of a regulatory framework for private assistance that made the segmentation explicit, formally abandoning any universalistic intent, and, on the other hand, those related to financing, which still are an object of dispute. The result is the consolidation of a dualistic health system - public and private.

Keywords: Health Policy; Implementation; Political Support; Financing; Feedback Effects.

\section{Introdução}

A literatura mais recente no campo da análise de políticas públicas tem chamado a atenção sobre a centralidade dos problemas de implementação, questionando a visão clássica de que a implementação é uma das fases do ciclo das políticas públicas, as quais executam as atividades necessárias para obtenção de metas definidas no processo de formulação. De acordo com essa perspectiva, problemas na implementação são considerados "desvios de rota", sem que seja problematizada sua própria formulação. A crítica a essa visão linear tem chamado a atenção sobre o aspecto processual do ciclo das políticas e sobre os efeitos retroalimentadores da implementação sobre a própria formulação, de tal forma que o processo de formação de uma política se dá a partir da interação entre formulação, implementação e avaliação (Pressman e Wildavisky, 1984; Lipsky, 1980, Lindblon, 198o; Barros e Melo, 2000; Molina, 2002; Grindle e Thomas, 1991; Meny e Thoenig, 1992).

Dado o caráter autônomo do processo de implementação, não há uma relação direta entre o conteúdo das decisões, que configuraram uma determinada política pública, e os resultados da implementação, que podem ser diferentes da concepção original. Seu sucesso está associado à capacidade de obtenção de convergência entre os agentes implementadores em torno dos objetivos da política e, particularmente, do suporte político dos afetados por ela. Além de ser um processo de adaptação, em função das mudanças do contexto, a implementação envolve decisões e, nesse sentido, é um processo que pode criar novas políticas.

Este artigo procura interpretar o processo de implementação da reforma do sistema de saúde ocorrida na década de 1990, quando se colocou a tarefa de transformar em realidade os dispositivos formais/legais, definidos na Constituição de 1988, que, como se sabe, trouxe importantes inovações no campo da saúde, ao consagrar o direito à saúde e ao definir princípios e diretrizes para orientar a política setorial, os quais, formalmente, alteraram significativamente $o$ padrão anterior, ao garantir o acesso universal, igualitário e gratuito às ações e aos serviços de saúde, considerados o objetivo fundamental da reforma da política de saúde. 
Algumas análises identificam o fracasso do Sistema Único de Saúde (SUS), expressão institucional da política de saúde, na medida que sua implementação se deu paralelamente à expansão e à consolidação do sistema privado (ou supletivo) de assistência à saúde. Esse processo foi algumas vezes visto como um efeito inesperado do processo de expansão de cobertura da assistência pública, configurando uma "universalização excludente" (Faveret Filho e Oliveira, 1990; Mendes, 1993, 1996, 2001; e Draibe, 1999). A maioria dos estudos sobre a implementação do SUS dá ênfase à questão do financiamento como ponto de estrangulamento na medida que o subfinanciamento do sistema de saúde não estaria garantindo a implantação dos princípios constitucionais, que deveriam garantir tanto a universalização do acesso quanto à ampliação da rede prestadora, esta última condição para a primeira. Na medida que a implantação do SUS coincide com uma conjuntura de crise e reformas econômicas, os efeitos das políticas de ajuste dos anos 1990 e o contexto nacional e internacional de reordenamento do papel do Estado e de crítica às políticas universalistas tendem a ser vistos como responsáveis pelos estrangulamentos no processo de implementação da política constitucionalmente definida e justificariam tanto o subfinanciamento quanto os incentivos à "privatização". Nesse último caso, o estabelecimento da política regulatória voltada para o segmento privado de assistência à saúde, ocorrido paralelamente ao processo de implementação do SUS, sinalizaria um redirecionamento das atribuições públicas no sentido de privatização, refletindo a inflexão da agenda da saúde, justificável nos termos do debate internacional, que passou a enfatizar políticas voltadas para o mercado, levando a uma convergência entre países (Laurell, 1995; Eibenschutz, 1995; Almeida, 1995, 1997; Viana, 1997).

Sem negar esses constrangimentos financeiros, políticos e ideológicos, é necessário interpretar o processo de implementação da reforma do sistema de saúde, problematizando essas explicações, relativizando a influência das variáveis contextuais, que levaram à configuração de uma nova agenda, e enfatizando os efeitos institucionais de dependência da trajetória da política de saúde prévia, particularmente, seus efeitos políticos. 0 ponto de partida para a construção do argumento defendido neste artigo é que, mais do que uma mera tradução prática de decisões, a implantação da reforma configurou-se, de fato, como um processo de formulação da política de saúde, cujo resultado seria a consolidação de um sistema híbrido público e privado -, apesar da definição legal de um sistema único, público, universal e gratuito. Nessa perspectiva, a implementação envolve decisões que podem redirecionar a política definida formalmente, e nesse processo a questão da viabilidade política é crucial, pois a sustentação política e a legitimidade da política são variáveis fundamentais para a implementação.

Para a análise do processo de implementação da reforma da política de saúde, parte-se do argumento de que a implantação de uma política exige decisão e iniciativa governamental, e instrumentos para efetivá-la, entre os quais a disponibilidade de recursos financeiros e suporte político organizado, particularmente, por parte dos grupos sociais afetados positivamente pela política. Foram analisadas as possibilidades de atendimento dessas exigências para a implantação do SUS, interpretando-as a partir da confluência dos efeitos da trajetória da política de saúde com fatores conjunturais de natureza econômica e política, em contexto de reformas econômicas e desfavorável à ampliação da atuação do Estado e de políticas universalistas. Os efeitos de feedback da configuração prévia de uma determinada estrutura institucional para a assistência à saúde manifestam-se de várias maneiras, afetando a disposição e a capacidade governamental e conformando as preferências e a interpretação da realidade dos atores que poderiam dar suporte político mais ativo à implantação da reforma.

Expressando a trajetória da política de saúde e seus efeitos institucionais, a implantação da reforma foi um processo cheio de contradições, pois, ao mesmo tempo que o SUS de fato se institucionalizou e se tornou uma realidade, contando inclusive com o apoio de novos atores constituídos a partir dele, sua implantação se fez em condições precárias e de forma incompleta, desvirtuando a concepção de seus formuladores. $\mathrm{Na}$ acomodação entre as definições legais, que deveriam ser implantadas, e o legado institucional anterior, configurou-se a política de saúde atual.

Este artigo é estruturado da seguinte forma: em primeiro lugar, são analisadas as condições políticas de implementação da reforma da política de saúde nos 
anos 1990, considerando os efeitos institucionais das políticas prévias, reforçados pela conjuntura de reconfiguração da agenda nacional e internacional; em segundo lugar, é analisada a questão do financiamento do SUS, qualificando a justificativa de ausência de recursos, vista aqui como expressão da ausência de uma disposição uniforme no âmbito governamental de implementação da reforma e não apenas como uma limitação de recursos, o que pressuporia uma disposição efetiva de materializar a assistência à saúde universal; em terceiro lugar, são analisados outros legados das políticas prévias sobre a capacidade governamental, o perfil dos usuários e os efeitos cognitivos, considerando seus efeitos sobre a sustentabilidade política do SUS e, particularmente, sobre a configuração da rede prestadora de serviços; por fim, são sintetizadas as principais conclusões.

\section{As Condições Políticas de Implementação da Reforma}

O contexto político nacional e internacional de implantação do SUS não se mostrou favorável. A configuração conservadora dos governos que se sucederam no período da transição democrática estava em perfeita sintonia com o ambiente internacional, marcado pela rediscussão do papel do Estado, e se traduzia em propostas de novos modelos de políticas sociais. A partir do questionamento da universalização de direitos, proliferaram propostas de focalização do gasto público nos setores mais pobres da população, deixando para o mercado a produção de serviços sociais destinados aos setores mais favorecidos. Ao processo de democratização seguiram-se os de ajuste e de estabilização econômica, acompanhados das reformas estruturais, em sentido inverso à ampliação das atribuições governamentais e dos direitos sociais recémconsagrados na Constituição, em sintonia com o receituário internacional. Como destacou Draibe (1995, p.219), antes que se implementassem as diretrizes da agenda de reforma social da transição democrática, desenhava-se outra agenda de reformas.

A conjuntura de crise fiscal, com suas conseqüências sobre o financiamento dos serviços públicos, associada ao fortalecimento de posições conservadoras e voltadas para o mercado, colocou constrangimentos à implantação do SUS, limitando a possibilidade de ampliação dos serviços de saúde, necessária para garantir a universalização efetiva. Para os gasto público isso funcionou como freio objetivo e ideológico para a atuação redistributiva do Estado.

A regulamentação do texto constitucional foi retardada, existindo setores contrários à implementação do SUS dentro do próprio governo, além de divergências intra-burocráticas sob a forma de sua operacionalização. A aprovação da Lei Orgânica da Saúde ocorreu dois anos depois da promulgação da Constituição e, apenas em 1992, o Executivo deu início ao processo de operacionalização do SUS. Na sua regulamentação, por meio de uma Norma Operacional, foram estabelecidos mecanismos que contrariavam dispositivos constitucionais, apontando a resistência à reforma no âmbito burocrático (Carvalho, in Goulart, 1996; Gerschman, 1995, entre outros).

A reforma fora resultado da ação política decorrente da emergência e da organização de novos sujeitos políticos, que, se aproveitando de uma conjuntura favorável de democratização, foram bem-sucedidos no processo de transformação de uma comunidade epistêmica, organizada em torno de uma concepção de saúde, em um grupo de ação política, capaz de definir um objetivo institucional. Para isso, aglutinaram aliados e interesses, como membros da academia, movimento médico, movimento popular, parlamentares, etc. A heterogeneidade na composição e nos posicionamentos políticos desse "movimento sanitário" evidenciou-se na implantação da reforma, quando se atualizaram as divergências de interesses, que durante o movimento pela redemocratização do país tinham sido escamoteados em função da agregação em torno da retomada do regime democrático e da reforma sanitária, enquanto projeto ético de caráter coletivo. Particularmente, acirram-se as divergências partidárias em decorrência do fortalecimento e da diversificação das identidades partidárias, propiciados pela democratização e aprofundaram-se o corporativismo entre o movimento médico que se distanciava do projeto básico da reforma sanitária no momento crucial de sua implementação (Gerschman, 1995). O movimento popular em saúde (MOPS), por sua vez, não foi capaz de garantir o apoio dos usuários dos serviços de saúde. Contribuiu para isso não apenas sua fraca mobilização política, mas a própria característica da reforma, que fez com que os seus benefícios fossem muito 
dispersos e só perceptíveis a longo prazo pelo conjunto da população, o que fez com que os responsáveis pela reforma não pudessem contar com o apoio mobilizado do público alvo da política de saúde.

Como expressão de seu enfraquecimento, após a aprovação da Lei Orgânica da Saúde, o movimento sanitário não teve mais uma atuação contínua e regular na legislação infraconstitucional, afastando-se do debate parlamentar (Rodrigues Neto, 1997).

Acresce-se a isso o fato de alguns atores, apesar de garantirem o apoio formal à reforma sanitária, não se constituírem de fato seus apoiadores efetivos, mergulhados nas contradições entre a postura ideológica igualitária e a defesa de seus interesses corporativos. Entre esses, destacou-se o movimento sindical mais combativo, cujas categorias, em grande parte, cobertas por planos privados de saúde, no âmbito das empresas e instituições públicas como efeito das políticas anteriores, não eram diretamente beneficiadas com a implantação do SUS e, nessa medida, não tinham incentivos concretos para apoiar de forma mais efetiva o sistema público.

A proposta de um sistema de saúde igualitário chocou-se com o legado histórico de uma sociedade marcada pela diferenciação e pela segmentação no próprio campo da atenção à saúde, no qual o processo de inclusão se deu pela incorporação de segmentos privilegiados dos trabalhadores assalariados. Como destaca Mendes (2001), as reformas sanitárias possuem um forte componente ideológico e expressam valores solidaristas vigentes, que, grosso modo, opõem-se a valores individualistas e auto-interessados. No caso brasileiro, a reforma foi de inspiração claramente solidarista, mas não se pode dizer que esses valores eram generalizados tanto na elite governante como na sociedade organizada. Ao contrário, como herança de políticas anteriores, tinham se desenvolvido práticas e, conseqüentemente, valores pouco solidaristas e não se constituíra uma demanda de atenção universal entre os segmentos organizados dos trabalhadores. A origem da assistência à saúde, calcada na diferenciação, primeiro no âmbito da assistência pública através dos Institutos de Aposentadoria e Pensão até os anos 1960 e, posteriormente, a partir da distinção entre trabalhadores cobertos por planos privados no âmbito das empresas, também como resultado de incentivos go- vernamentais, e os cobertos pela assistência pública, não favoreceu a constituição de uma identidade coletiva e de valores que enfatizassem a solidariedade e o igualitarismo que pudessem dar suporte à reforma, que, pelo seu caráter redistributivo, demandaria coalizões mais amplas. Concomitante à implementação da reforma a demanda por assistência médica diferenciada da pública transformou-se em item da agenda de negociação coletiva de diversas categorias de trabalhadores, constituindo-se um "veto implícito" ao modelo público e universal e fortalecendo a assistência diferenciada prestada pelas empresas (Costa, 1995).

O projeto de ruptura no padrão de intervenção estatal na área da saúde e a concretização da agenda redistributiva e universalista confrontaram-se com o desenho histórico da cidadania regulada, ao mesmo tempo que não existia "um projeto nacional de desenvolvimento que tomasse a questão da desigualdade e da exclusão como o cerne da questão democrática" Fleury (1997, p.34)

Embora a postura oficial do movimento sindical mais combativo, representado pela Central Única dos Trabalhadores, seja a de defesa do sistema público e de direitos igualitários, na prática, isso não se traduz em mobilização efetiva pela concretização dos princípios do SUS. A discussão da saúde no cotidiano dos sindicatos tem se centrado nas questões da saúde do trabalhador, vinculadas às condições de trabalho e aos benefícios previdenciários, que passaram a consumir muito das energias do movimento sindical, diante da sua vulnerabilidade e do acúmulo de perdas com o aumento do desemprego desde os anos 1990. Pela participação nos fóruns colegiados da estrutura do SUS, as lideranças do movimento sindical integram-se ao SUS, mas a questão não parece ter atingido a categoria como um todo, demonstrando contradição entre os interesses imediatos e a orientação político-ideológica de defesa das ações públicas de cunho universalista. Cada vez mais desenvolve-se o que uma liderança sindical chamou de "cultura de planos de saúde", que se tornou uma demanda dos trabalhadores e que dificilmente encontra resistência das empresas (Sintel, 2002).

Esse paradoxo se evidencia mais expressiva por se tratar de atores encarregados da operacionalização da assistência médica pública, nas entidades repre- 
sentativas dos servidores públicos das instituições previdenciárias, que são cobertos pela GEAP, o maior plano de saúde na modalidade de autogestão do país e um dos mais antigos. Apesar da defesa radical de um sistema único e público nos fóruns formais da categoria, na prática, os beneficiários da GEAP sempre defenderam duramente o que consideravam "direitos adquiridos" de uma assistência médica diferenciada e de maior qualidade (GEAP, 1990; Menicucci, 1987²).

A descentralização tem provocado o surgimento de novos apoiadores do SUS no nível das prefeituras e das instâncias colegiadas, que se organizaram a partir de definições legais no sentido de incluir a participação da sociedade na gestão do SUS. Esse processo de constituição de novos sujeitos na arena da saúde é muito recente para que possa surtir resultados que alterem a dinâmica política para reforçar o SUS em detrimento do processo de segmentação das clientelas decorrente do fortalecimento do setor privado a partir dos anos 1960 e, de forma acentuada, nas décadas seguintes. Ainda nessa arena local, funcionários das prefeituras e membros dos conselhos de saúde, em muitos casos, também estão cobertos por planos de saúde coletivos, assumindo freqüentemente posições corporativas (Fundação João Pinheiro, 1998).

\section{O Financiamento do SUS como Forma de Inviabilização Sistêmica}

A operacionalização da reforma da política de saúde implicava transformações político-institucionais e organizacionais de grande envergadura, sendo o grande esforço inicial promover a descentralização. Para o alcance dos objetivos finalísticos da reforma, o financiamento é um recurso imprescindível, envolvendo não apenas o volume, mas a forma de repasse dos recursos do governo federal para estados e municípios, uma vez que a descentralização se fez na dependência dos recursos federais, principais responsáveis pelo financiamento das ações de saúde: cerca de $80 \%$ até o final da década de 1980 e 70\% na década de 1990 (MS/Secretaria de Gestão de Investimentos em Saúde, 2001:5); reduzindo-se recentemente para 52\% (MS/ SCTIE-DES, apud Conasems, 2004).
A questão do financiamento tornou-se o "calcanhar de Aquiles” para a efetivação da reforma, pois não foi garantido maior aporte de recursos necessários para efetivar a universalização de cobertura e a realização dos investimentos necessários à ampliação da rede pública de serviços. A ausência de fontes estáveis de financiamento, os constantes atrasos nos repasses da União para estados e municípios levou a uma degradação da qualidade dos serviços bastante acentuada nos primeiros anos do SUS.

Às deficiências do financiamento têm sido creditadas as principais dificuldades para a implantação do SUS. Em um contexto de programas de estabilização e de ajuste fiscal, caracterizado por cortes nas despesas públicas, particularmente, nos gastos sociais, tornou-se sedutor atribuir a esse panorama geral a deficiência de recursos para a viabilização do SUS.

Reconhecendo esses constrangimentos, cabe indagar em que medida havia de fato a intenção governamental de implantar os dispositivos formais da política de saúde, mas que seria inviabilizada pelas limitações financeiras. $\mathrm{O}$ argumento desenvolvido neste artigo é que mesmo não negada no discurso, nem mesmo tendo sido objeto de uma redução programática, a atenção à saúde universal e igualitária foi objeto de veto implícito e de inviabilização sistêmica, por analogia com a noção de redução sistêmica das políticas do estado de bem-estar, utilizada por Pierson (1994). Com essa expressão, Pierson refere-se às estratégias indiretas para a redução de políticas cujas conseqüências são sentidas apenas em longo prazo e que parecem ter sido muito mais importantes nas tentativas de desmantelamento do Estado de bem-estar do que nos esforços de redução programática explícita dos programas sociais.

A ausência de mecanismos efetivos e estáveis para o financiamento do SUS funcionou como um mecanismo indireto para a redução de seu alcance e efetividade mesmo que no discurso dominante, em geral, não são questionados os fundamentos básicos do SUS. Algumas tentativas de mudanças estruturais no SUS, relacionadas aos princípios da universalidade e da integração da atenção, partiram do governo federal, mas não lograriam apoio para serem encaminhadas,

2 MENICUCCI, Telma M. G. Assistência patronal: a negação da previdência social no seu próprio seio. Belo Horiozonte: Departamento de Sociologia e Antropologia da FAFICH-UFMG, 1987. 
como a PEC 32, que propunha alterar o artigo 196 da Constituição e que visava estabelecer limites ao direito à saúde e restringir o dever do Estado na provisão das condições para seu exercício (Barros, 1998).

Com o panorama político, normativo e institucional descrito, não é razoável supor que houvesse, de fato, a intenção de reverter as características do modelo de atenção à saúde. Dado o custo político de uma redução programática das propostas do SUS, em um quadro de consolidação da democracia, a estratégia indireta de inviabilização sistêmica, não garantindo o aporte de recursos necessários à operacionalização do SUS, parece consistente. A descrição da trajetória do financiamento feita a seguir esclarece este argumento.

Ao definir um orçamento específico para a Seguridade Social, que, além da Saúde, inclui a Previdência e a Assistência, a Constituição buscou assegurar fontes para seu financiamento, mas às restrições orçamentárias, somou-se o desvio de recursos da seguridade social por diferentes mecanismos, como: sonegação ou inadimplência por parte das empresas; utilização de recursos da seguridade social para cobrir despesas do orçamento fiscal ou de outros Ministérios; e retenção de recursos do seu orçamento. Em função das perdas decorrentes do novo federalismo fiscal, após a Constituição de 1988, que transferiu recursos para estados e municípios, a União passou a disputar os recursos das contribuições sociais que representam mais da metade da sua receita tributária.

A própria configuração institucional da destinação de recursos para o segmento saúde tornou-o fragilizado diante do segmento previdenciário da Seguridade Social e do Executivo Federal, na medida que não era o arrecadador de nenhuma de suas receitas e não foram definidas vinculações explícitas para a saúde dentre as diversas fontes que compõem o orçamento da seguridade. A partir de 1988, houve um crescimento acentuado dos valores arrecadados pela Seguridade Social, mas que não se refletiu na mesma proporção no segmento saúde, o qual se caracterizou por grande instabilidade na alocação de recursos federais (Fundação João Pinheiro, 1999; Lucchesi, 1996).

Sob a alegação de que tinham designação exclusiva para o pagamento dos benefícios previdenciários (aposentadorias e pensões), a partir de maio de 1993 , o Ministério da Previdência Social suspendeu unilateralmente o repasse dos recursos sobre a folha de pagamento para o custeio das ações de saúde. Nesse mesmo ano, o presidente da República vetou o artigo da Lei de Diretrizes Orçamentárias, que destinava 30\% dos recursos do Orçamento da Seguridade Social para a saúde, conforme previsto nas disposições transitórias da CF, sob a alegação de ser contrário ao interesse nacional.

Outras fontes do Orçamento da Seguridade Social, como a contribuição sobre o Lucro Líquido e a Contribuição do Financiamento Social, além de disputados por outras áreas do governo, enfrentaram questionamento jurídico no meio empresarial no início dos anos 1990, cuja conseqüência foi a indisponibilidade desses recursos por algum tempo. A crise gerada nesse momento provocou uma discussão sobre a necessidade de novas e estáveis fontes de financiamento para a saúde. Mesmo supondo que a efetivação da reforma sanitária nos termos propostos por seus idealizadores não figurasse na agenda concreta de ações e escolhas, o mau funcionamento do sistema de saúde público passou a ser uma das faces mais vulneráveis da política social do governo. Apesar dos avanços expressivos em termos de cobertura, da realização de serviços, dos ganhos nos indicadores de saúde e da maior racionalidade e eficiência na gestão dos recursos propiciadas pela descentralização e incorporação do controle democrático por meio do modelo de gestão participativa que fez parte da reforma, os problemas do SUS ganharam muita visibilidade e passaram a ser denunciados em diferentes perspectivas.

A partir de um diagnóstico da crise, centrado no financiamento, na segunda metade da década de 1990, as evidências e as críticas sobre insuficiência e irregularidade dos recursos destinados ao SUS ganharam maior visibilidade e propostas alternativas entraram na agenda pública. Sob forte pressão do então ministro da Saúde, Adib Jatene, para a criação de uma fonte adicional de recursos para financiamento do SUS, que redundou em sua demissão por incompatibilização com a área econômica do governo, e contando com fortes resistências tanto no Congresso quanto nos diferentes segmentos sociais a serem afetados, foi instituída, em 1996, a Contribuição Provisória sobre Movimentação Financeira (CPMF), mediante a Emenda Constitucional $n^{0}$. 12/1996 que, na sua primeira versão, definia que a receita proveniente dessa arrecadação deveria ser destinada integralmente para o finan- 
ciamento das ações e dos serviços de saúde. Sua aprovação ocorreu sem mobilização social ampla. Ao contrário, grupos de pressão ligados ao empresariado, à mídia e a outros posicionaram-se contrários ao vigor (Goulart, 1996). A oposição era previsível, uma vez que, ao ser uma nova tributação a incidir sobre as movimentações bancárias, atingiria exatamente os setores que, na sua maioria, não se constituíam em usuários do SUS - a estimativa é de que a CPMF atingisse aproximadamente $18 \%$ da população, apenas a parcela que mantém contas na rede bancária nacional. Considerando que cerca de $25 \%$ da população é coberta por planos de saúde privados e que essa cobertura tem uma relação com níveis de renda e qualidade do emprego (PNAD, 1998), é razoável supor que exista uma sobreposição entre esses dois grupos.

Entretanto, a nova fonte, que deveria constituir um recurso supletivo, tornou-se substitutivo, na medida que passaram a ser desviados recursos de outras fontes do orçamento da Seguridade Social, que em grande parte se destinavam ao setor saúde, como o Cofins e a Contribuição Social sobre o Lucro de Pessoas Jurídicas. Em 1996, a execução orçamentária do Ministério da Saúde foi de 14,4 bilhões de reais, sem a CPMF. Em 1997, esse orçamento passou a ser de 20,5 bilhões de reais, com uma estimativa de arrecadação inicial de aproximadamente 5,3 bilhões de reais da CPMF. Todavia, a arrecadação da CPMF no ano de 1997 foi de 6,7 bilhões, valor 1,4 de bilhão superior ao inicialmente previsto. Soma-se a este fato o contingenciamento de 1,7 bilhão no orçamento do Ministério da Saúde, que executou apenas 18,8 bilhões em 1997. Isso significa que, em 1997, a saúde teve 3,1 bilhões de reais a menos, sendo 1,4 bilhão de excesso de arrecadação da CPMF e 1,7 bilhão de corte no orçamento aprovado no Congresso Nacional (Fundação João Pinheiro, 1999, p.129).

A ausência de fluxos regulares de recursos para a saúde gerou um movimento nacional, conhecido como "Movimento SOS SUS", em torno da vinculação de recursos para o setor. Contando com a resistência da área econômica do governo, a proposta só se constituiu norma legal com a aprovação da Emenda Constitucional $n^{0}$. 29/200o, que garantia recursos mínimos para o financiamento do SUS, sob a forma de vinculação de recursos orçamentários dos diversos níveis de governo. Após sete anos de tramitação de várias PECs, a discussão só avançou no Congresso a partir de 1998, após obter o apoio explícito do presidente da República e por pressão do então ministro da Saúde, José Serra, oriundo da área econômica e pertencente ao partido do presidente, que exerceu o papel de policy advocate da Emenda.

A mobilização pela obtenção de recursos para o financiamento do SUS envolveu principalmente os gestores municipais e estaduais, os Conselhos de Saúde dos três níveis de governo, os conselhos de secretários de saúde e as entidades representativas de prestadores de serviços e de profissionais de saúde, atores que, direta ou indiretamente, seriam beneficiados pela EC, embora por diferentes razões: os gestores, por estarem premidos pela demanda de serviços e pela escassez de recursos, e os prestadores de serviço, insatisfeitos com a remuneração de seus serviços pelo Poder Público, vendo nessa PEC uma possibilidade de aumentar seus rendimentos pela garantia de maior estabilidade no financiamento da saúde. No Congresso, contou-se com o apoio da Frente Parlamentar de Saúde, de caráter informal e multipartidária, além de outras entidades, como a CNBB e o Fórum de Trabalhadores.

Com a pressão do chefe do Executivo, quando era muito criticado por ter negligenciado as questões sociais, e sob a condução do presidente da Câmara, foi realizado um acordo suprapartidário para aprovar, em tramitação acelerada, tal como queria o ministro da Saúde e com modificações consensuadas entre lideranças partidárias e governo, a PEC nº. 82/95, do deputado Carlos Mosconi, do partido governista. Apesar da existência de divergências entre ministros e forte resistência de governadores, por significar a vinculação de recursos em um quadro de difícil situação financeira dos estados, a PEC foi aprovada, com encaminhamento unânime de todos os partidos. Veja depoimento colhido em entrevista com Rafael Guerra (2002), médico, deputado federal integrante da Frente Parlamentar da Saúde:

Fomos ao Presidente do Congresso, ao Presidente da Câmara, ao Ministro da Saúde, ao Ministro do Planejamento, ao Secretário da Casa Civil, ao Secretário Geral da Presidência, ao José Serra (...) e a movimentação foi se ampliando, com a participação da Pastoral da Igreja, da Associação Médica Brasileira, Conselho Federal de Medicina e os outros Conselhos de Especialidades, o Conass (Conselho dos Secretários 
Estaduais de Saúde), o Conasems (Conselho Nacional de Secretários Estaduais de Saúde). Houve audiências públicas, passeatas, reuniões com bancadas dos partidos (...) Isso durou quase um ano. Ao final, depois de todas as resistências do Ministério da Fazenda e do Ministério do Planejamento - que eram contra as vinculações orçamentárias, por engessar o orçamento e impedir o Ministro do Planejamento de tomar decisões sobre as prioridades do Governo -, depois de vencer todos os problemas, de discutir exaustivamente o assunto, o Presidente da Republica apoiou a votação da emenda constitucional, com a condição de que ela implicasse também o financiamento pelos Estados e Municípios.

Embora a EC 29 não tenha sido proposta diretamente pelo Executivo, ele não deixou de definir a agenda tanto no conteúdo substantivo quanto no ritmo de sua aprovação. A emenda sofreu as alterações propostas pelo Executivo que conseguiu definir uma descentralização dos encargos financeiros com saúde e preservar a União de uma vinculação mais explícita de recursos para a saúde. Substantivamente, apenas para os estados, municípios e Distrito Federal foi estabelecida uma vinculação de recursos orçamentários, mediante a destinação de um percentual definido dos seus orçamentos para o custeio das ações de saúde a ser atingido de forma gradual. Para a União, a EC 29/ 2000 definiu provisoriamente uma ampliação percentual dos gastos absolutos efetuados pela União no ano anterior e remeteu para uma Lei Complementar a definição dos percentuais mínimos a serem alocados na saúde. Com esse adiamento, a definição dos encargos federais com saúde foi deixada ao sabor da conjuntura política, mantendo-se, em certa medida, a vulnerabilidade do orçamento da saúde, na medida em que os recursos federais ainda eram majoritários para o custeio das ações de saúde.

A mudança de postura do Executivo federal, ao passar a defender a aprovação da vinculação de recursos para a saúde, não sugere uma intenção de ampliar os gastos federais para o custeio do sistema de saúde. Ao contrário, evidencia, em primeiro lugar, o propósito de deslocar a questão do financiamento da saúde do nível federal para as instâncias subnacionais de governo, forçando-as a ampliar sua participação no gasto em saúde e, em segundo lugar, a intenção de desvincular da saúde os recursos da CPMF, o que exigi- ria como contrapartida o estabelecimento de nova fonte de custeio para o setor. A tentativa de tramitação acelerada da EC coincide com a aproximação do término da vigência da CPMF, aprovada inicialmente para ser provisória e destinada à saúde, mas que, de fato, tornara-se uma importante fonte de receitas para o governo federal. Prorrogada, por meio da EC 21/1999, os recursos decorrentes da arrecadação da CPMF passaram a ser direcionados para o custeio da Previdência Social, deixando legalmente de ter a destinação exclusiva para a saúde, que justificara sua criação. As intenções do governo federal transparecem em depoimento do ministro da Saúde em audiência pública realizada em maio de 1998, durante os trabalhos da Comissão Especial constituída para proferir parecer à PEC 29, conforme estabelece a legislação, realizada antes da alteração da CPMF:

(...) além da necessidade de um mínimo Nacional Ipara financiamento do SUSJ, seria muito importante um mínimo federal para que tivéssemos proporções entre União, Estados e Municípios... A CPMF não é uma receita específica da saúde. Aliás, o Congresso Nacional não a aprovou como tal. O Congresso aprovou uma receita da Seguridade Social. Portanto, a CPMF, hoje, está financiando déficit da Previdência.

Essa mudança foi mais um veto implícito ao setor saúde, ao mesmo tempo que, por meio de um jogo de contradições, defendia-se e conseguia-se, aparentemente, a aprovação de mais recursos para a saúde. A desconfiança sobre a intenção do governo de solucionar o problema de financiamento do SUS foi claramente expressa por parte dos parlamentares oposicionistas e até os da base governista durante a tramitação da "PEC Saúde". Essa desconfiança baseava-se em um conjunto de ações em sentido contrário, como os constantes contingenciamentos do orçamento da saúde, a utilização dos recursos arrecadados com a CPMF fora do setor saúde e a retenção de recursos da seguridade social para o Fundo de Estabilização Fiscal. Além disso, outras decisões governamentais não sugeriam uma postura de fortalecimento do setor público, como: a regulamentação dos planos e seguros de saúde, concomitantemente à discussão da vinculação de recursos para o financiamento do SUS, que apontou o interesse de alavancar o crescimento do mercado privado de assistência à saúde; a abertura de hospitais públicos, particularmente os universitários, para cli- 
entelas privadas via convênios como forma de arrecadar recursos adicionais e que tinha como conseqüência a restrição de vagas para pacientes do SUS; e a proposta de transformar os hospitais públicos em organizações sociais juridicamente privadas, a fim de torná-los mais eficientes e auto-sustentáveis.

A forma de cumprimento da EC 29 sugere a falta de empenho governamental para solucionar o problema do subfinanciamento do SUS. Uma forma de frear o aumento de recursos da União para o sistema de saúde público deu-se mediante conflito intraburocrático entre diferentes interpretações da legislação. Se, no caso da vinculação dos recursos estaduais e municipais a legislação foi auto-aplicável, para os recursos da União, exercícios 2001/2004, período de transição até a definição de Lei Complementar, a implementação foi polêmica. No momento de implantação da reforma, Embora o texto legal não sugerisse dúvidas sobre a forma de cálculo dos recursos mínimos a serem aplicados pela União, houve um choque entre duas interpretações jurídicas. Por um lado, coincidiam as interpretações da Procuradoria Geral da Fazenda Nacional/Ministério da Fazenda, apoiada por parecer da Advocacia Geral da União e, por outro, a interpretação da Consultoria Jurídica e da Subsecretaria de Planejamento e Orçamento do Ministério da Saúde, do Conselho Nacional de Saúde e do Tribunal de Contas da União, defendida pela chamada "Bancada da Saúde" no Congresso Nacional. A controvérsia está centrada principalmente na base de cálculo a ser utilizada para os valores sobre os quais a União deverá aplicar os aumentos anuais dos recursos aplicados na saúde.

A divergência intraburocrática relativa à interpretação da forma de aplicação da emenda constitucional na definição concreta dos montantes a serem alocados pelo governo federal aponta para a inexistência de um projeto global de governo para a concretização do SUS, explicitada pela divergência entre as agências encarregadas da política econômica e da saúde. Na prática, o governo tem adotado como referência para a fixação dos tetos orçamentários para o setor saúde a interpretação da Procuradoria Geral da Fazenda Nacional e da Advocacia Geral da União, decisão que se traduz em prejuízos para o setor. Um documento do Conasems (2004) apontou o valor de R\$ 1,8 bilhão como diferença acumulada no não-cumprimento, por parte do governo federal da EC 29, nos anos de 2001, 2002 e 2003, ado- tando a interpretação do TCU. A transferência de parte da responsabilidade do custeio da saúde para as instâncias subnacionais de governo vem ocorrendo de forma acentuada para os municípios que, em grande parte, desde o ano de 2000 já vêm cumprindo o previsto na EC 29 (SIOPS). Grande parte dos estados não está cumprindo as determinações da emenda, em função da falta de disponibilidade de recursos, em uma conjuntura caracterizada pelo endividamento e pelo alto comprometimento das suas receitas.

Tudo indica que os aportes adicionais de recursos, esperados a partir da EC 29, não têm sido significativos a ponto de reverter o quadro de subfinanciamento do SUS, particularmente, para garantir recursos para investimentos - ponto frágil do sistema. Está também na dependência da Lei Complementar a definição das formas de fiscalização, avaliação e controle das despesas com saúde nas esferas federal, estadual e municipal. Em 2004, terminou o período de transição previsto na EC 29 e começou a tramitar um Projeto de Lei que a regulamenta. 0 projeto prevê a aplicação de, no mínimo, $10 \%$ das receitas correntes da União, o que significaria um aumento do montante que vem sendo aplicado. A julgar pelo debate recente durante a tramitação da proposta de Reforma Tributária, ocasião em que os estados tentaram alterar as vinculações de receita, parece pouco provável que essa vinculação também de recursos da União seja aprovada dessa forma. Isso mostra que a participação dos entes federados no financiamento do SUS continua sendo contestada. Caso essas questões não sejam resolvidas, a EC 29 corre o risco de ser mais uma definição meramente formal para a viabilização dos princípios constitucionais relativos à saúde, persistindo a sua inviabilização sistêmica.

\section{Constrangimentos Institucionais: efeitos de feedback sobre a rede de serviços e perfil dos usuários, $e$ efeitos cognitivos}

Em função de sua própria natureza, a efetivação da política de saúde implica a existência de uma rede prestadora de serviços. As características e a evolução dessa rede evidenciam que as conseqüências das decisões governamentais anteriores constituem en- 
traves de natureza estrutural à efetivação dos dispositivos constitucionais. As políticas estabelecidas a partir dos anos 1960 forneceram incentivos e recursos que facilitaram a expansão da rede prestadora privada, o que teve como seu principal efeito a consolidação de uma forte dependência do setor privado para a realização de procedimentos de maior complexidade. A opção do passado pela compra de serviços, principalmente hospitalares, tendeu a ser readotada, na medida que não se desenvolveram capacidades estatais para uma opção diferente. A forte penetração dos interesses dos prestadores privados nas instituições governamentais, através dos anéis burocráticos da Previdência Social, garantiu que esses interesses fossem protegidos, e não se desenvolveu uma ação reguladora eficiente para garantir a preservação do interesse público na compra de serviços.

A universalização da assistência e a definição da saúde como relevância pública, que caracterizaram a reforma do final dos anos 1980, não foram acompanhadas da efetiva publicização da rede prestadora, seja pela expansão da rede estatal em níveis e na diversidade exigidos seja pela incorporação da rede privada de acordo com critérios públicos. Ao longo das duas últimas décadas, ocorreu a ampliação da rede pública, principalmente, ambulatorial, que cresceu aproximadamente $80 \%$, após 1988, bem mais do que o crescimento dos estabelecimentos com internação, que tiveram uma expansão de aproximadamente 42\% (AMS/ IBGE, 1988, 1989, 1990, 1992, 1999, 2002)3. Essa expansão mostra o esforço efetivo para a universalização da assistência, a partir da garantia de acesso à atenção primária e pode também ser relacionada ao aprofundamento do processo de descentralização, gerando maior pressão sobre os governos locais para o atendimento das demandas de assistência, sendo esse tipo de atenção prescindível de investimentos de maior vulto, inacessíveis a esses governos. A expansão da rede hospitalar é apenas pontual, e não há indícios de que a situação possa se alterar, tanto em função da limitação de recursos destinados a investimentos como por não ser considerada questão na agenda pública.

O legado dessa escolha do passado gerou, na atualidade, a necessidade de regulação governamental mais forte para, de fato, publicizar a rede privada disponível para o SUS, fazendo valer o interesse público em função do imperativo legal de garantir o acesso universal. As limitações para uma regulação mais efetiva são grandes e incluem dificuldades operativas do sistema público para definir sua demanda, negociar serviços, implantar e fiscalizar contratos, o que impõe fortes custos de transação em uma relação que ainda não tem regras definidas nem desenvolveu a capacidade reguladora entre os gestores públicos. As restrições políticas são também significativas na medida que o setor privado, com forte tradição de autoregulação ou de regulação governamental, limitada à definição de preços e controle da produção dos serviços e impõe fortes resistências. A resistência dos prestadores, a falta de atuação concertada dos agentes públicos para uma regulação mais rigorosa e efetiva das relações com a rede privada e a repetição inercial dos padrões de regulação anterior caracterizam a persistência de uma relação ainda bastante frágil, que garanta a regularidade na prestação pelo sistema público dos serviços de saúde de maior complexidade, para os quais é grande a dependência da rede privada.

Essas resistências são favorecidas pelo formato dual da assistência à saúde, constituída por essa mistura de privado e público, pois aos prestadores de serviços existe a alternativa do mercado de planos de saúde, que permite prescindir do SUS. A trajetória da assistência à saúde no Brasil levou ao desenvolvimento de um mercado de serviços de saúde com vários agentes privados tanto para a demanda como para a produção de serviços. Nesse mercado, o setor público acabou se tornando mais um, embora maior, agente comprador de serviços, na medida em que não se configurou uma assistência pública de fato universal, mas um modelo híbrido. Embora a natureza jurídica dos estabelecimentos hospitalares não impeça por si só a publicização da rede ou dos serviços contratados, a configuração institucional do sistema de saúde coloca constrangimentos para que se consiga fazer prevalecer o interesse público sobre o privado. A implantação do contrato de direito público na relação com o setor privado, definido na Constituição, ainda não se tornou realidade nacional ou geral. Mesmo com sua 3 PEQUISA de Assistência Médica Sanitária - AMS/IBGE. Anos: 1976, 1977, 1978, 1979, 1980, 1981, 1982, 1983, 1984, 1985, 1986, 1987,
1988, 1989, 1990, 1992,1999. 
existência não há alteração significativa na relação governo-prestador privado, que ainda ocorre com uma priorização da lógica privada da oferta, e não a lógica da demanda ou das necessidades da população. A falta de controle sobre o setor privado expressa-se também na persistência de mecanismos para garantir o acesso a atendimentos hospitalares, que fogem às regras universalistas do SUS, e favorecem o atendimento de segmentos privilegiados da população, caracterizando uma forma perversa de interpenetração entre o sistema público e o privado.

Como outro efeito de feedback da política de saúde, sugerido a partir de pesquisa qualitativa com uma amostra de pessoas (Menicucci, 2003), a trajetória dual da assistência e a experiência com os seus dois formatos têm efeitos cognitivos sobre os usuários e não apenas sobre os gestores, ao influenciar a percepção e conformar as imagens sobre o sistema de saúde. Embora existam diferenças acentuadas entre a avaliação dos serviços de saúde efetivamente utilizados e a opinião sobre eles, a imagem geral sobre o sistema público, construída a partir da comparação com o privado, é bastante negativa. A falta de sintonia entre as avaliações sobre a qualidade dos serviços públicos utilizados, na sua maioria bastante positivas, e as opiniões expressas sobre eles apontam para a força de representações construídas e alimentadas sobre o "caos da saúde" no Brasil, entendendo-se, por isso, a partir de uma redução sumária, os serviços prestados pelo SUS.

Expressões das restrições ao acesso são as queixas reiteradas sobre filas e demora no atendimento, elementos que acabam caracterizando o sistema público, em contraponto à imagem explicitada a respeito do sistema privado, cujas principais qualidades identificadas são exatamente a comodidade e a presteza do atendimento.

A diferença entre a imagem e a realidade do atendimento expressa-se de forma mais aguda entre aqueles que não são usuários do sistema público, que, em geral, são os que têm a pior opinião sobre ele, o que é a justificativa para a inserção no sistema privado para quem tenha condições para isso. Por sua vez, as opiniões sobre os planos privados não são muito positivas, pois recebem críticas quanto ao seu caráter lucrativo em detrimento da preocupação assistencial, o que se traduz em restrições de cobertura e preços muitos altos. A inserção na assistência privada aparece não como uma opção pelo mercado, mas como uma necessidade diante da "baixa qualidade" da assistência pública, e é o desejo da maioria dos entrevistados. A ambigüidade jurídico-institucional da assistência à saúde do país acaba, assim, por se reproduzir no discurso da população, também crivado de ambigüidades.

Essa análise das imagens e das opiniões sobre a assistência pública e privada, embora seja extraída de uma amostra não representativa, sem condições de generalização, sugere a hipótese de que essa percepção dos dois sistemas assistenciais tenha como conseqüência o baixo apoio fornecido pela população ao sistema público, mesmo que no nível formal reproduzam a noção consagrada na Constituição, ao reafirmarem que a prestação de serviços de saúde é um direito que deveria ser garantido pelo Poder Público ao cidadão. É logicamente plausível supor que a contrapartida do fraco apoio ao sistema público seja o reforço do privado, se não como integrado ao ideário da assistência, mas a partir de uma descrença no público. Atuaria, também, como alternativa supostamente "realista", ou mais adequada do ponto de vista da relação meios/fins, mas que, de fato, traduz as imagens construídas a partir da inserção no sistema privado, e não necessariamente como decorrência da utilização do sistema público, o que nunca foi uma realidade para uma expressiva parcela da população que transitou da medicina liberal para os planos privados.

Expressão e consolidação dessa dualidade, bem como do volume e importância que o segmento privado assumiu, concomitantemente às mudanças institucionais no sentido de implantação do SUS, na década de 90 ganhou relevo o debate envolvendo diferentes atores, tanto governamentais quanto da sociedade civil, sobre a regulamentação da "assistência médica supletiva”. Esse debate culminou com a promulgação da Lei 9665, em 6/1998, que dispõe sobre os planos privados de assistência à saúde. Em vez de um indicativo simplista de "fracasso" do SUS, a regulamentação mostra que se tratou de colocar sob o controle governamental atividades que já estavam suficientemente institucionalizadas, de forma que o dispositivo constitucional que garantiu a assistência pública a todos por si só não desmoronaria. A regulamentação não fará nada mais do que completar o processo de 
consolidação do sistema de saúde dual do país, confrontando a lógica da assistência médica como uma mercadoria ou um produto à lógica do SUS, baseada na noção de direito de cidadania, formalizando as conseqüências de processos e de decisões anteriores e, principalmente, o arranjo dual.

\section{Conclusões}

O processo de implementação da reforma da política de saúde definida na CF 1988 teve início na década de 1990 e é simplesmente a tradução concreta de decisões, mas um processo ainda de formulação da política de saúde. Neste sentido, refletem não apenas os efeitos do contexto político-econômico de ajustes e a reconfiguração da agenda pública, mas principalmente os efeitos de feedback das políticas de saúde anteriores, que se traduziram na ausência de suporte político, no subfinanciamento e na incapacidade de publicização da rede de serviços, os quais funcionaram como constrangimentos à implementação completa da reforma da política de saúde nos termos de seus formuladores. Dentro desses limites, foram tomadas decisões cruciais que redefiniram a reforma, sendo as mais significativas, o estabelecimento do marco regulatório da assistência privada, que explicita a segmentação e derruba formalmente as pretensões universalistas, e, as relativas ao financiamento, que ainda são objeto de disputa.

No momento de implantação da reforma, a falta de suporte político efetivo de categorias sociais relevantes, seja por sua atuação no setor saúde, ou seja, por sua maior capacidade de mobilização, pode ser visto como um efeito da trajetória da política de saúde, que teve como resultado a configuração de um sistema dual, público e privado, que segmentou os usuários a partir de sua inserção em cada um deles. Como umas das conseqüências dessa segmentação, constituíram-se preferências e representações sobre o público e o privado pouco favoráveis ao SUS.

O movimento sanitário, mentor principal da mudança, não se constituiu como grupo de interesse, mas como conjunto de pessoas e instituições que em um momento singular de refundação democrática, partilharam um conjunto de valores éticos e de propostas políticas e técnicas com o objetivo de democratização do sistema de saúde. Essa "identidade" foi forjada na conjuntura autoritária, que permitiu a minimização dos interesses particularistas, mas mostrou sua fragilidade e descontinuidade no momento de implantação da reforma sanitária, quando as alianças mais amplas não lograram se sustentar. Após a redemocratização, as diferentes clivagens explicitaram-se e não se conseguiu mais uma homogeneidade de propostas, tanto pelas fraturas ideológicas internas do movimento sanitário e do movimento popular quanto pela retomada das questões meramente corporativas de atores que se tinham aglutinado ao movimento, particularmente, os profissionais médicos e os trabalhadores e os sindicatos com maior nível de organização e maior poder de barganha. Esses, embora mantivessem o apoio ideológico ao SUS, no período de implementação, de fato não tinham muitos incentivos para uma transformação publicista da assistência à saúde que, pelo menos em curto prazo, lhes traria perdas objetivas, na medida em que, na sua maioria, deveriam estar vinculados a planos de saúde empresariais, a essa altura institucionalizados e constituindo-se, muitas vezes, em objeto de negociação coletiva.

Por sua vez, os prováveis usuários do SUS, os segmentos excluídos da assistência privada, seja pela menor renda ou pela forma de inserção mais precária no mercado de trabalho, não demonstraram capacidade de mobilização que pudesse dar sustentação à reforma, que, por suas características redistributivas, demandaria coalizões mais amplas, particularmente em uma situação institucionalizada de diferenciações e privilégios.

Essa falta de suporte refletiu na ausência de uma demanda universalista entre os trabalhadores e as categorias profissionais que traduzisse a existência de uma identidade coletiva e o desenvolvimento de valores solidaristas que pudessem se expressar no apoio efetivo à proposta do SUS. Nada disso foi favorecido pela trajetória de expansão dos direitos sociais no país, entre eles a assistência à saúde. Esta, ao contrário, se deu com base em um modelo meritocrático, desenvolveu-se favorecendo as demandas corporativas no âmbito das instituições previdenciárias e, após o surgimento e desenvolvimento da assistência empresarial, tornou-se um benefício particularizado, dependendo da forma de inserção no mercado de trabalho.

0 veto implícito à implantação da reforma em sua completa acepção não veio dos segmentos favoreci- 
dos pela assistência privada. Por meio de mecanismos indiretos, particularmente, a indefinição e a ausência de fontes estáveis de financiamento, o próprio governo não garantiu a viabilização dos objetivos da reforma. A aprovação da EC 29/200o, que teoricamente vincula recursos dos três níveis de governo para a saúde, não demonstra que a questão terá uma solução satisfatória. Como a principal fonte de recursos para custeio da assistência pública é de origem federal, as divergências relativas à base de cálculo para a definição da contribuição da União têm se traduzido em alocação de recursos aquém do esperado com a aprovação da EC. A transferência dos encargos financeiros para as unidades subnacionais de governo sugere o menor comprometimento do governo federal com o financiamento do SUS, caracterizando um processo de inviabilização sistêmica, mesmo que não se manifestem propostas explícitas de redução programática do escopo do SUS. Por sua vez, o descumprimento da EC 29 por muitos estados sugere que as ações de saúde ainda não se tornaram uma prioridade.

A conjuntura econômico-financeira não foi favorável à implantação do SUS, que, para sua efetivação, necessitaria de uma ampliação de recursos proporcional à expansão da clientela e de suas atribuições, o que não foi propiciado pela situação de recessão econômica. Entretanto, isso não significa que o problema seja apenas a falta da capacidade de implementação, particularmente, financeira, pois isso pressupõe que existiria, o objetivo estatal de implantação dos dispositivos constitucionais, ou seja, um sistema público de caráter universal e igualitário. Ao que tudo indica, um projeto publicista para a saúde não se constituiu como objetivo governamental. Os princípios do SUS conseguiram ser definidos como política de governo em função de uma conjuntura privilegiada, caracterizada pela redemocratização, mas sua implantação ocorreu em um quadro político dominado por forças políticas conservadoras e em contexto marcado pela perda de apoio e legitimidade de políticas sociais universalistas e pela valorização do mercado em detrimento da ampliação da esfera de atuação do Poder Público.

Outros efeitos da trajetória da política de saúde impuseram constrangimentos objetivos na consolidação de um sistema de saúde de fato único. Se a ausência de uma rede de serviços coloca limitações formais, os costumes e os códigos de conduta, desenvolvidos no contexto de experiências com o sistema dual, oferecem limitações informais, podendo ser impenetráveis a mudanças no sentido de unificação da assistência à saúde. De algum modo, as escolhas do passado naturalizamse e conformam a preferência por serviços privados.

Entretanto, apesar das restrições, o SUS foi se institucionalizando, inclusive pelo reconhecimento público do direito à saúde. Nesse processo, outros atores se constituíram e passaram a disputar espaço na arena da saúde, particularmente os gestores municipais e estaduais e os conselhos paritários, formados nos três níveis de governo como exigência da legislação. Além desses, dada a importância do SUS como o principal comprador de serviços de saúde, ele (o SUS) consegue apoio, pelo menos nas questões relativas ao financiamento, dos prestadores privados e dos profissionais de saúde, cujos interesses são diretamente afetados pela política de saúde. Esse apoio é cheio de ambigüidades, na medida que é dispensado da mesma maneira ao segmento privado uma vez que os segmentos público e privado partilham, em grande parte, a mesma rede de serviços.

Duas lógicas operam no processo de implementação da política de saúde: uma publicista, que visa viabilizar o SUS, processo que de certa forma se tornou irreversível, e outra privatista, que visa ampliar a cobertura por planos e seguros de saúde, constituindo, ou consolidando dois segmentos diferenciados, que se traduzem em duas estruturas institucionais. Os dois processos confluem e conformam a política de saúde vigente, em um movimento ainda em formação e que aponta para vários desfechos possíveis. As decisões dos implementadores no contexto econômico, político e institucional em que operam apontam para a distância entre a concepção dos formuladores iniciais da reforma e sua implementação, que tem sido, de fato, a consolidação de um sistema de saúde dual.

\section{Entrevistas}

1. Rafael Guerra, médico, Deputado Federal pelo PSDBMG, em 26/5/2002.

2. Ruth de Lourdes da Conceição Costa. Diretora de Saúde do SINTEL e membro do Coletivo de Saúde Intersindical da CUT/MG, em dezembro de 2002.

3. 90 moradores de Belo Horizonte, em junho de 2002. 


\section{Referências}

ALMEIDA, Célia Maria de. As reformas sanitárias dos anos 8o: crise ou transição? 1995. Tese (Doutorado) Fundação Oswaldo Cruz/Escola Nacional de Saúde Pública, Rio de Janeiro, 1995.

ALMEIDA, Célia Maria de. Crise econômica, crise do Welfare State e reforma sanitária. In: GERSCHMAN, S.; VIANNA, M. L. W. (Org.). A miragem da pós-modernidade: democracia e políticas sociais no contexto da globalização. Rio de Janeiro: Fiocruz, 1997. p. 177-200.

CONASEMS - Conselho Nacional de Secretários Municipais de Saúde. Notícias, o1 set. 2004.www.conasems. org.br acesso em 07 set. 2004.

COSTA, Nilson do Rosário. Políticas públicas, direitos e interesses: reforma sanitária e organização sindical no Brasil. In: EIBENSCHUTZ, Catalina (Org.). Política de saúde: o público e o privado. Rio de Janeiro: Fiocruz, 1995. p. 345-362.

DRAIBE, Sonia. Repensando a política social: dos anos 80 ao início dos 9o. In: SOLA, L.; PAULANI, L. M. (Org.). Lições da década de 8o. São Paulo: Edusp, 1995 p. p. 201221.

DRAIBE, Sonia. As políticas sociais nos anos 199o. In: BAUMANN, Renato (Org.). Brasil: uma década em transição. Rio de Janeiro: Campus, 1999. p. 101-142.

EIBENSCHUTZ, Catalina. Apresentação. In: EIBENSCHUTZ, Catalina (Org.). Política de saúde: o público e o privado. Rio de Janeiro: Fiocruz, 1995. p. 11-18.

FAVERET FILHO, Paulo; OLIVEIRA, Pedro Jorge de. A universalização excludente: reflexões sobre as tendências do sistema de saúde. Dados - Revista de Ciências Sociais, Rio de Janeiro, vol. 33, n. 2, 199o, p. 257-283.

FLEURY, Sonia. A questão democrática na saúde. In: FLEURY, Sonia (Org.). Saúde e democracia: a luta do CEBES. São Paulo: Lemos, 1997. p. 25-41.

FUNDAÇÃO JOÃO PINHEIRO. Descentralização e governança no setor saúde em Belo Horizonte. Belo Horizonte, 1998.

FUNDAÇÃO JOÃO PINHEIRO. A reforma do sistema de saúde do Brasil: a descentralização como diretriz e a igualdade como princípio. Belo Horizonte, 1999.
GEAP - Fundação de Seguridade Social. Os dilemas em torno da Patronal. Jornal da Patronal, Belo Horizonte, ano 2, n. 3, p. 4, out. 1990

GERSCHMAN, Silvia. A democracia inconclusa: um estudo da reforma sanitária brasileira. Rio de Janeiro: Fiocruz, 1995.

GOULART, Flávio A. de Andrade. Municipalização: veredas - caminhos do movimento municipalista de saúde no Brasil. Rio de Janeiro: Abrasco: Conasems, 1996.

GRINDLE, Merilee S.; THOMAS, John W. Public choices and policy change. Baltimore, MD: Johns Hopkins University, 1991.

LAURELL, Asa Cristina. La lógica de la privatizacion em salud. In: EIBENSCHUTZ, Catalina (Org.). Política de saúde: o público e o privado. Rio de Janeiro: Fiocruz, 1995. p. 31-48.

LINDBLON, Charles Edward. The policy-making process. Indianápolis, IN: Prentice Hall, 1980.

LIPSKY, Michel. Street Level Bureaucrats. Nova York: Russel Sage, 1980.

LUCCHESI, Patrícia T. R. Descentralização do financiamento e gestão da assistência à saúde no Brasil: a implementação do Sistema Único de Saúde - retrospectiva 1990/1995. Planejamento e Políticas Públicas, Brasília, n. 14, p. 75-156, dez. 1996.

MENDES, Eugênio Vilaça. As políticas de saúde no Brasil nos anos 80: a conformação da reforma sanitária e a construção do projeto neoliberal. In: MENDES, Eugênio Vilaça (Org.). Distrito sanitário: o processo social de mudança das práticas sanitárias do Sistema Único de Saúde. São Paulo: Hucitec; Rio de Janeiro: Abrasco, 1993.

MENDES, Eugênio Vilaça. Uma agenda para a saúde. São Paulo: Hucitec, 1996.

MENDES, Eugênio Vilaça. Os grandes dilemas do SUS. Salvador: Casa da Qualidade, 2001.

MENICUCCI, T. M. G. Público e privado na política de assistência à saúde no Brasil: atores, processos e trajetória. Tese de doutorado. FAFICH/UFMG, 2003.

MENY, Yves; THOENIG, Jean-Claude. Las politicas públicas. Barcelona: Ariel, 1992. 
MOLINA, Carlos Geraldo. Modelo de formacion de politicas y programas sociales. Washington, DC: BID: INDES, 2002.

PESQUISA NACIONAL por Amostra de Domicílios PNAD/IBGE, 1998. Microdados.

PIERSON, Paul. Dismantling the welfare state?: Reagan, Thatcher, and the politics of retrenchment. Cambridge. Local de Publicação: Cambridge University Press, 1994.

PRESSMAN, Jeffrey L.; WILDAVISKY, Aaron. Implementation. Berkeley, CA: University of California Press, 1984 .
RODRIGUES NETO, Eleutério. A via do parlamento. In: FLEURY, Sonia (Org.). Saúde e democracia: a luta do CEBES. São Paulo: Lemos, 1997. p. 63-91.

SILVA, Pedro Luiz Barros; MELO, Marcus André Barreto. $O$ processo de implementação de políticas públicas no Brasil: características e determinantes da avaliação de programas e projetos. Campinas: NEPP: Unicamp, 200o. (Caderno, 48).

VIANA, Ana Luiza. As políticas sociais e as políticas de saúde no contexto do processo de globalização. In: GERSCHMAN, S.; VIANNA, M. L. W. (Org.). A miragem da pós-modernidade: democracia e políticas sociais no contexto da globalização. Rio de Janeiro: Fiocruz, 1997. p. 201-210. 